\title{
Struktur dan Konduktivitas Ionik Kaca LiMNPO 4 sebagai Katoda pada Baterai Sekunder
}

\author{
S. Qomariyah, W. Widanarto*, W. T Cahyanto \\ Jurusan Fisika, Universitas Jenderal Soedirman, Jl. dr. Soeparno 61 Purwokerto 53123, Indonesia \\ *Corresponding Author: wahyu.widanarto@unsoed.ac.id
}

\begin{abstract}
Abstrak - Katoda kaca Lithium Manganese Phosphates $\left(\mathrm{LiMnPO}_{4}\right)$ telah dibuat melalui reaksi solid state dan metode melt quenching pada temperatur $900{ }^{\circ} \mathrm{C}$ dengan komposisi $5 \mathrm{Li}_{2} \mathrm{CO}_{3}: \mathrm{x} \mathrm{MnO}_{2}: 15 \mathrm{ZnO}:(80-\mathrm{x}) \mathrm{P}_{2} \mathrm{O}_{5}$ (dimana $\mathrm{x}=0 ; 1,5$ dan 3 dalam $\%$ mol). Karakterisasi sifat termal katoda yang meliputi temperatur transisi kaca $T$ g dilakukan dengan Differential Scanning Calorimetry (DSC). Pengaruh penambahan $\mathrm{MnO}_{2}$ terhadap struktur dan konduktivitas ionik katoda kaca dipelajari dengan menggunakan $X$-ray Diffraction (XRD) dan LCR meter. Pola difraksi $X R D$ yang diperoleh menunjukkan bahwa struktur semua katoda adalah amorf. Konduktivitas ionik katoda meningkat dengan bertambahnya konsentrasi $\mathrm{MnO}_{2}$, namun konduktivitas cenderung menurun pada konsentrasi $\mathrm{MnO}_{2}$ yang berlebihan. Nilai konduktivitas ionik tertinggi katoda sebesar $7,25 \times 10^{-4} \mathrm{~S} / \mathrm{cm}^{2}$ ditunjukkan oleh katoda kaca yang mengandung $1,5 \% \mathrm{MnO}_{2}$. Berdasarkan pengujian voltametri siklik dan charge/discharge, katoda kaca $\mathrm{LiMnPO}_{4}$ sangat berpotensi untuk digunakan dalam baterai Lithium sekunder.

Kata kunci: Baterai ion Lithium, Katoda Kaca, Lithium Manganese Phosphates, Konduktivitas Ionik, Baterai Sekunder
\end{abstract}

\begin{abstract}
Glass Cathodes of Lithium Manganese Phosphates $\left(\mathrm{LiMnPO}_{4}\right)$ are prepared using the melt quenching method at temperatures of $900{ }^{\circ} \mathrm{C}$ with composition $5 \mathrm{Li}_{2} \mathrm{CO}_{3}: \mathrm{x}_{\mathrm{MnO}_{2}}: 15 \mathrm{ZnO}:(80-\mathrm{x}) \mathrm{P}_{2} \mathrm{O}_{5}$ (where $\mathrm{x}=0,1.5$ and $3 \mathrm{~mol} \%$ ). Thermal properties of the cathodes including a glass transition temperature $(\mathrm{Tg})$ are characterized using Differential Scanning Calorimetry (DSC). Influence of the $\mathrm{MnO}_{2}$ addition on structure and ionic conductivity of cathodes are studied using X-ray Diffraction (XRD) and LCR meters, respectively. XRD diffraction patterns show that all of the cathode structures are amorphous. The ionic conductivity of the cathode increases with increasing of $\mathrm{MnO}_{2}$ concentration, but the conductivity tends to decrease at the excessive concentration of $\mathrm{MnO}_{2}$. The highest ionic conductivity of the cathode is $7.25 \times 10^{-4} \mathrm{~S} / \mathrm{cm}$, exhibited by the glass cathode containing $1.5 \mathrm{~mol} \%$ of $\mathrm{MnO}_{2}$. According to cyclic voltammetry and charge/discharge tests, the $\mathrm{LiMnPO}_{4}$ glass cathodes are very potential to be used in Secondary Lithium Battery.

Keywords: Lithium ion batteries, Glass Cathode, Lithium Manganese Phosphates, Ionic Conductivity, Secondary battery
\end{abstract}

\section{PENDAHULUAN}

Perkembangan teknologi di bidang perangkat elektronik portable seperti handphone, tablet, kamera digital, laptop yang semakin canggih memicu permintaan penyimpanan energi listrik yang lebih maju pula. Baterai yang merupakan salah satu komponen penyimpan energi, kini terus diteliti dan dikembangkan untuk menghasilkan spesifikasi yang lebih baik. Salah satu jenis baterai yang saat ini sedang banyak dikembangkan yaitu baterai lithium. Baterai lithium terdiri dari tiga komponen utama yaitu elektrolit, anoda dan katoda. Suatu baterai ion lithium harus memiliki katoda yang dapat menahan suhu tinggi dan memiliki mobilitas ion lithium yang tinggi.
Salah satu material katoda yang saat ini mulai banyak dikembangkan, yaitu katoda tipe olivine seperti $\mathrm{LiMnPO}_{4}$ dan $\mathrm{LiFePO}_{4}$. Katoda $\mathrm{LiMnPO}_{4}$ memiliki kapasitas teoritis yang sama seperti katoda $\mathrm{LiFePO}_{4}$ yakni sekitar $170 \mathrm{mAh} / \mathrm{g}$. $\mathrm{LiMnPO}_{4}$ memiliki working-potential yang relatif lebih tinggi yaitu mendekati $4 \mathrm{~V}\left(\mathrm{vs} . \mathrm{Li}^{+} / \mathrm{Li}\right.$ ) bila dibandingkan dengan $\mathrm{LiFePO}_{4}$ yang hanya berkisar 3,5 V (vs. $\mathrm{Li}^{+} / \mathrm{Li}$ ). Potensial kerja yang dimiliki $\mathrm{LiMnPO}_{4}$ membuatnya memiliki densitas energi yang lebih tinggi dan biaya produksi yang lebih rendah daripada $\mathrm{LiFePO}_{4}[1]$. Katoda $\mathrm{LiMnPO}_{4}$ juga memiliki stabilitas termal yang baik, ramah lingkungan, dan aman digunakan sebagai bahan katoda menjanjikan untuk sistem baterai masa depan. Kelemahan dari katoda ini yaitu, nilai konduktivitas elektronik dan 
konduktivitas ioniknya jauh lebih rendah $\left(<10^{-10}\right.$ $\mathrm{S} / \mathrm{cm})$ dibandingkan dengan $\mathrm{LiFePO}_{4}\left(1,8 \times 10^{-9}\right.$ $\mathrm{S} / \mathrm{cm})$, hal tersebut menyebabkan sifat elektrokimia dan laju difusi ion lithiumnya rendah. Beberapa penelitian telah banyak dilakukan guna meningkatkan konduktivitas listrik $\mathrm{LiMnPO}_{4}$, diantaranya yaitu pelapisan dengan karbon, pelapisan dengan logam atau logam oksida, doping dengan ion, serta optimasi ukuran partikel dan morfologi.

Baterai lithium ion beroperasi berdasarkan pada pergerakan ion-ion lithium, sehingga material katoda pada baterai lithium harus mempunyai konduktivitas ion yang tinggi untuk dapat menghantarkan ion-ion lithium dengan cepat. Gambar 1 menunjukkan proses charge dan discharge pada baterai lithium, selama pelucutan muatan (discharge) logam Li pada anoda akan teroksidasi membentuk ion-ion $\mathrm{Li}^{+}$dan elektronelektron $\left(\mathrm{Li}^{\rightarrow} \mathrm{Li}^{+}+\mathrm{e}^{-}\right)$. Ion lithium yang dihasilkan bergerak dari anoda melalui elektrolit menuju ke katoda baterai, sedangkan elektron bergerak melalui suatu rangkaian listrik luar. Kebalikan dari proses tersebut adalah proses pengisian muatan (charging). Reaksi yang terjadi pada proses ini yaitu, terjadi reaksi oksidasi pada katoda yang menghasilkan elektron-elektron, oksigen dan ion-ion Li. Ion-ion lithium meninggalkan katoda dan berdifusi melalui elektrolit ke anoda. Bersamaan dengan perpindahan ion lithium, elektron juga ditransfer kembali ke anoda melalui suatu rangkaian luar. [2]

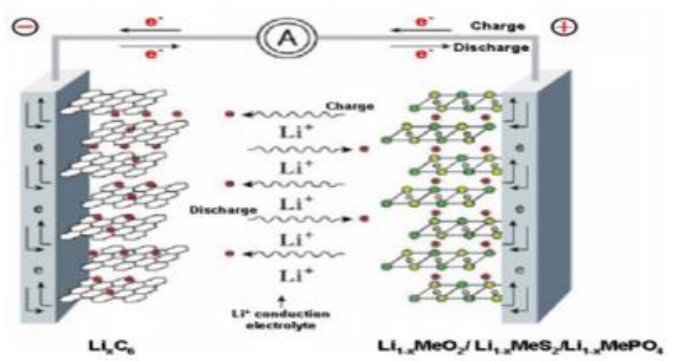

Gambar 1 Proses discharge dan charge pada baterai ion lithium

Pada penelitian ini akan dilakukan pembuatan katoda kaca $\mathrm{LiMnPO}_{4}$ dengan proses sintesis solid state reaction dan metode melt quenching (pendinginan pada suhu ruang). Katoda $\mathrm{LiMnPO}_{4}$ akan dibuat dalam bentuk kaca, karena kaca memiliki banyak keuntungan, yaitu dapat dibuat dengan berbagai pilihan komposisi, bersifat isotropik, tidak ada batas butir, dapat disintesis baik pada suhu rendah dan tinggi serta kontrol parameter yang mudah. [3]

\section{METODE}

Pembuatan katoda kaca dilakukan di Laboratorium Fisika Eksperimen dan Kimia Anorganik FMIPA UNSOED. Katoda kaca dibuat dengan komposisi $5 \mathrm{Li}_{2} \mathrm{CO}_{3}: \mathrm{xMnO}_{2}$ : $15 \mathrm{ZnO}:(80-\mathrm{x}) \mathrm{P}_{2} \mathrm{O}_{5}(\mathrm{x}=0 ; 1,5 ;$ dan 3 dalam $\%$ mol). Variasi perbandingan komposisi diperlihatkan pada tabel berikut :

Tabel 1 Variasi komposisi pembuatan katoda kaca $\mathrm{LiMnPO}_{4}$

\begin{tabular}{|l|l|l|l|l|}
\hline $\begin{array}{l}x \\
(\%)\end{array}$ & $\begin{array}{l}\mathrm{Li}_{2} \mathrm{CO}_{3} \\
(\%)\end{array}$ & $\begin{array}{l}\mathrm{MnO}_{2} \\
(\%)\end{array}$ & $\begin{array}{l}\mathrm{ZnO} \\
(\%)\end{array}$ & $\begin{array}{l}\mathrm{P}_{2} \mathrm{O}_{5} \\
(\%)\end{array}$ \\
\hline 0 & 0.05 & 0 & 0.15 & 0.8 \\
\hline 1.5 & 0.05 & 0.015 & 0.15 & 0.785 \\
\hline 3 & 0.05 & 0.03 & 0.15 & 0.77 \\
\hline
\end{tabular}

Campuran kelima bahan tersebut diletakkan dalam cawan crucible dan dipanaskan pada electrical furnace A (sebagai furnace pertama) pada temperatur sekitar $900{ }^{\circ} \mathrm{C}$ dan ditahan selama 90 menit. Lelehan kaca kemudian dituangkan di atas lempeng steinless steel yang sebelumnya telah dipanaskan terlebih dahulu pada electrical furnace B (sebagai furnace pertama) yang suhunya dijaga konstan pada 300 ${ }^{\circ} \mathrm{C}$. Lelehan kaca tersebut ditahan di dalam electrical furnace selama 3 jam, kemudian kaca diangkat dan didinginkan mengeras pada temperatur ruang.

Karakterisasi katoda kaca dilakukan di PSTBM BATAN dan P2F LIPI Serpong. Proses karakterisasi sampel katoda kaca diawali dengan membuat pellet dan serbuk dari katoda kaca yang telah terbentuk, pellet dibuat dengan diameter $13 \mathrm{~mm}$ menggunakan press hydrolic dengan tekanan 1 ton. Kaca $\mathrm{LiMnPO}_{4}$ yang telah berbentuk pellet kemudian dikarakterisasi DSC untuk mengetahui suhu transisi gelas, karakterisasi XRD untuk mengetahui struktur kristal dari masing-masing sampel katoda kaca, 
dan pengujian konduktivitas ionik menggunakan LCR meter .

Proses pengujian performa elektrokimia sel baterai katoda kaca $\mathrm{LiMnPO}_{4}$ diawali dengan pembuatan slurry. Slurry terdiri dari $\mathrm{LiMnPO}_{4}$ sebagai material aktif, $\mathrm{PVDF}, \mathrm{AB}$ (Acetylene Black) dan DMAC, dengan perbandingan $85 \%$ Material akif $\left(\mathrm{LiMnPO}_{4}\right): 15 \%$ PVDF : $5 \%$ AB. Massa DMAC dihitung dari $20 \mathrm{x}$ massa PVDF. Proses selanjutnya yaitu coating, slurry dilapiskan di atas lembaran alumunium foil dan kemudian dikeringkan di atas hotplate. Lembaran yang telah kering dipotong membentuk lingkaran berdiameter $23 \mathrm{~mm}$. Sel baterai disusun di dalam holder, terdiri dari lembaran katoda, separator, anoda (lithium metal) dan elektrolit $\left(\mathrm{LiFP}_{6}\right)$, proses ini berlangsung di dalam glove box yang dialiri gas Argon. Rangkaian sel baterai tersebut kemudian diuji performa elekrtokimianya menggunakan cyclic voltammetry dan chargeldischarge.

\section{HASIL DAN PEMBAHASAN Pembuatan Sampel Kaca LiMnPO}

Sampel katoda kaca $\mathrm{LiMnPO}_{4}$ dibuat dengan menggunakan metode melt quenching. Bahanbahan yang digunakan dalam pembuatan katoda kaca $\mathrm{LiMnPO}_{4}$, yaitu $\mathrm{Li}_{2} \mathrm{CO}_{3} \mathrm{MnO}_{2} \mathrm{ZnO}$, dan $\mathrm{P}_{2} \mathrm{O}_{5}$. Bahan $\mathrm{Li}_{2} \mathrm{CO}_{3}$ digunakan sebagai pengubah lithium yaitu untuk memperoleh $\mathrm{Li}_{2} \mathrm{O}$, sedangkan $\mathrm{ZnO}$ merupakan bahan modifier (pengubah kaca) yang berfungsi sebagai penstabil pada proses pembuatan kaca, $\mathrm{P}_{2} \mathrm{O}_{5}$ merupakan bahan pembentuk kaca phospat, sedangkan $\mathrm{MnO}_{2}$ merupakan bahan yang digunakan sebagai dopping yang komposisinya divariasikan.

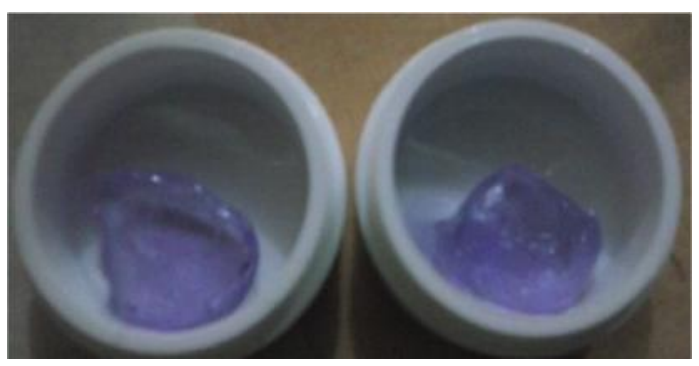

Gambar 3 Sampel kaca $\mathrm{LiMnPO}_{4}$
Katoda kaca yang telah terbentuk ditumbuk dengan menggunakan mortar hingga halus dan homogen. Serbuk kaca kemudian dicetak menggunakan cetakan pellet berdiameter $13 \mathrm{~mm}$ dan di press menggunakan hydrolic press pada tekanan 1 ton dan penahanan 3 menit.

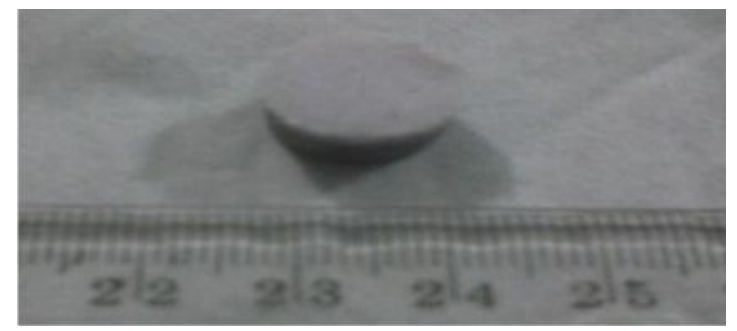

Gambar 4 Sampel kaca $\mathrm{LiMnPO}_{4}$ dalam bentuk pellet

\section{Struktur Katoda Kaca LiMnPO}

Karakterisasi struktur katoda kaca $\mathrm{LiMnPO}_{4}$ menggunakan XRD dilakukan pada rentang $2 \theta$ antara $20^{\circ}-80^{\circ}$ dengan panjang gelombang $\mathrm{CuK} \alpha$ 1,54 A. Karakterisasi XRD dilakukan untuk menunjukkan struktur kristal dari kaca $\mathrm{LiMnPO}_{4}$, pada umumnya kaca berstruktur armorf. Material dengan struktur armorf mempunyai susunan atom yang tidak teratur, hal ini berbeda dengan material kristalin, dimana atom-atomnya tersusun rapi. Ketidakteraturan susunan atom pada struktur amorf inilah yang diharapkan dapat memberikan ruang lebih untuk ion-ion lithium dapat bergerak bebas.

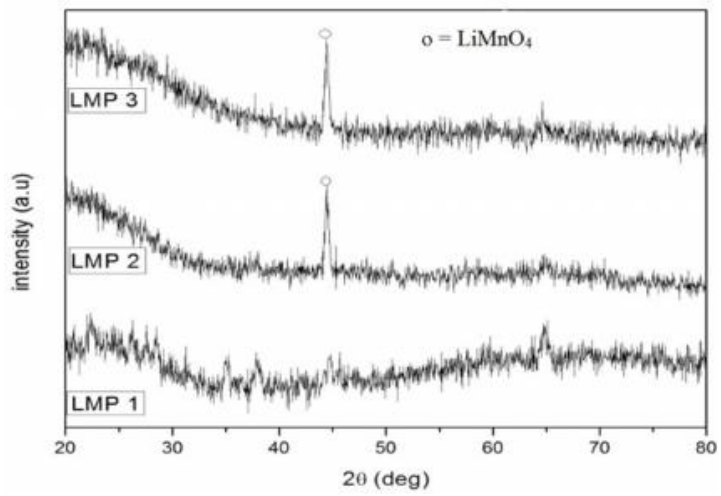

Gambar 5 Spektrum XRD Katoda Kaca $\mathrm{LiMnPO}_{4}$

Hasil pola difraksi XRD menunjukkan ketiga sampel katoda kaca yang dihasilkan memiliki struktur amorf. Hal ini dapat dilihat bahwa pola difraksi XRD tersebut melebar dan tidak adanya puncak-puncak (peak) yang signifikan. Pola ini berbeda dengan material kristalin yang memiliki 
lebih dari satu peak difraksi. Namun, ada sebuah peak yang terlihat pada sampel kedua dan ketiga yaitu pada posisi $2 \theta=44,41^{\circ}$. Berdasarkan data ICDD Nomor 04-017-2508 dan Nomor 00-0521841 diketahui bahwa peak tersebut menunjukkan fase $\mathrm{LiMnO}_{4}$. Munculnya peak ini kemungkinan karena pada proses pencampuran bahan tidak homogen atau masih adanya pengotor. Pembuatan katoda kaca dilakukan dengan metode solid state, metode ini diketahui mempunyai kekurangan yaitu sampel yang dihasilkan kurang homogen. Hal ini juga berkaitan dengan bahan yang digunakan dalam pembuatan katoda kaca, yaitu $\mathrm{P}_{2} \mathrm{O}_{5}$ yang bersifat hygroscopics (mudah mengikat oksigen). Bahan $\mathrm{P}_{2} \mathrm{O}_{5}$ ini mudah menggumpal ketika bereraksi dengan udara sehingga pada saat pencampuran tidak semua bahan tercampur merata.

Pembuatan katoda khususnya untuk tipe olivine sebaiknya dilakukan dengan mengontrol atmosphere, salah satu cara yang dapat dilakukan yaitu dengan menempatkan sampel pada kondisi inert (dialiri gas Nitrogen/Argon). Dengan kontrol atmosphere yang tepat dapat dihasilkan sampel dengan sedikit pengotor (impurity) serta dapat mengurangi terjadinya reaksi-reaksi yang tidak diperlukan, seperti reaksi pengikatan terhadap oksigen. Qi Lu, dkk membuat katoda $\mathrm{LiMnPO}_{4}$ didopping $\mathrm{Mg}$ dengan pemanasan pada kondisi inert untuk membuat material yang homogennya [4], penelitian terkait juga dilakukan oleh Kinamura, dkk dengan tujuan untuk meningkatkan konduktivitas material. [5]

\section{Sifat Termal Katoda Kaca LiMnPO}

Karakterisasi DSC yang dilakukan pada penelitian ini hanya untuk mengetahui nilai transisi kaca $\left(T_{g}\right)$. Sampel pada karakterisasi DSC dipanaskan dari suhu $30{ }^{\circ} \mathrm{C}$ sampai $450{ }^{\circ} \mathrm{C}$ pada laju $10{ }^{\circ} \mathrm{C} /$ menit.

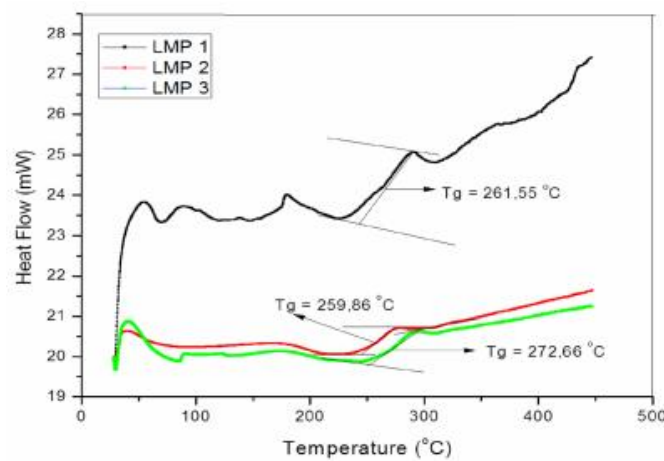

Gambar 6 Grafik DSC Katoda Kaca $\mathrm{LiMnPO}_{4}$

Selama rentang temperatur dari $0{ }^{\circ} \mathrm{C}$ sampai 500 ${ }^{\circ} \mathrm{C}$ terjadi reaksi eksotermik atau reaksi pelepasan panas yang ditunjukkan dengan adanya kenaikan nilai temperatur dan reaksi penyerapan panas atau endotermik saat terjadi penurunan nilai perubahan temperatur $(T)$. Temperatur transisi gelas $\left(T_{g}\right)$ teramati saat ada perubahan reaksi eksotermik menuju reaksi endotermik secara tibatiba dari sampel kaca yang menyebabkan penurunan nilai perbedaan temperatur secara tibatiba pada kurva.

\section{Konduktivitas Katoda Kaca LiMnPO}

Pengukuran konduktivitas pada sampel katoda kaca dilakukan menggunakan alat LCR meter pada range frekuensi $1 \mathrm{~Hz}-100 \mathrm{KHz}$ dengan tegangan acuan sebesar 1 Volt.

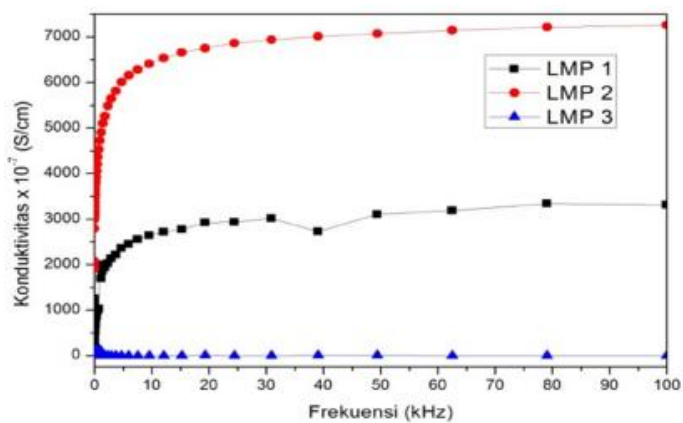

Gambar 7 Grafik Konduktivitas Katoda Kaca $\mathrm{LiMnPO}_{4}$

Perubahan nilai konduktivitas pada kurva menandakan adanya pergerakan ion yang terjadi pada sampel katoda kaca selama proses pengujian LCR meter. Nilai konduktivitas untuk masingmasing sampel secara jelas disajikan pada tabel berikut ini : 
Tabel 3 Nilai Konduktivitas katoda kaca $\mathrm{LiMnPO}_{4}$

\begin{tabular}{|l|l|l|}
\hline Sampel & $\begin{array}{l}\text { Konduktivitas } \\
\min (\mathrm{S} / \mathrm{cm})\end{array}$ & $\begin{array}{l}\text { Konduktivitas } \\
\text { maks }(\mathrm{S} / \mathrm{cm})\end{array}$ \\
\hline LMP-1 & $2,73 \times 10^{-5}$ & $3,34 \times 10^{-4}$ \\
\hline LMP-2 & $1,90 \times 10^{-4}$ & $7,25 \times 10^{-4}$ \\
\hline LMP-3 & $3,77 \times 10^{-9}$ & $1,20 \times 10^{-5}$ \\
\hline
\end{tabular}

Nilai konduktivitas katoda kaca mencapai nilai maksimum pada komposisi $\mathrm{MnO}_{2} \quad 1,5 \%$, sedangkan pada komposisi 3\% nilai konduktivitas cenderung menurun. Penambahan konsentrasi $\mathrm{MnO}_{2}$ dapat meningkatkan nilai konduktivitas, namun ada batasan nilai tertentu dimana konduktivitas justru cenderung menurun dengan semakin bertambahnya konsentrasi $\mathrm{MnO}_{2}$. Menurunnya nilai konduktivitas pada komposisi 3\% ini disebabkan karena terlalu banyaknya konsentrasi $\mathrm{MnO}_{2}$ dapat menghambat laju pergerakan dari ion-ion lithium. Konsentrasi $\mathrm{MnO}_{2}$ yang tinggi dalam katoda menurunkan mobilitas ion karena adanya tumbukan saat diterapkan dengan medan listrik kecil. Ion mengalami tumbukan dan kehilangan sebagian atau seluruh energi kinetiknya. Akibatnya, kecepatannya berkurang diikuti oleh penurunan mobilitas dan konduktivitas ionik. ${ }^{[3]}$

Nilai konduktivitas tertinggi yang didapat adalah sebesar $7,25 \times 10^{-4} \mathrm{~S} / \mathrm{cm}$, yaitu pada sampel katoda dengan komposisi $\mathrm{MnO}_{2}$ 1,5\%. Jika kita bandingkan dengan beberapa penelitian sebelumnya terkait pembuatan katoda baterai, nilai konduktivitas yang didapat pada penelitian ini sudah lumayan besar. Seperti yang disebutkan oleh Guo bahwa konduktivitas $\mathrm{LiMnPO}_{4}$ yaitu sekitar $<10^{-10} \mathrm{~S} / \mathrm{cm}^{[6]}$

\section{Performa Katoda kaca $\mathrm{LiMnPO}_{4}$ sebagai Sel Baterai}

Performa kaca $\mathrm{LiMnPO}_{4}$ sebagai katoda pada rangkaian sel baterai dapat diuji dengan menggunakan cyclic voltametry. Hasil dari Cyclic voltametry berupa voltamogram, yaitu grafik hubungan antara tegangan terhadap arus. Sel baterai diberikan tegangan pada range tertentu, kemudian diukur besarnya arus yang terjadi.

Berdasarkan voltamagram dapat diketahui adanya peak oksidasi dan peak reduksi. Sel baterai yang menunjukkan adanya peak oksidasi dan reduksi maka menyatakan bahwa material tersebut mampu mengalami proses charge dan discharge, hal ini merupakan syarat dasar sebagai baterai sekunder (recheargable). Voltamogram hasil pengujian Cyclic Voltametry untuk sampel katoda kaca $\mathrm{LiMnPO}_{4}$ ditunjukkan pada gambar berikut :

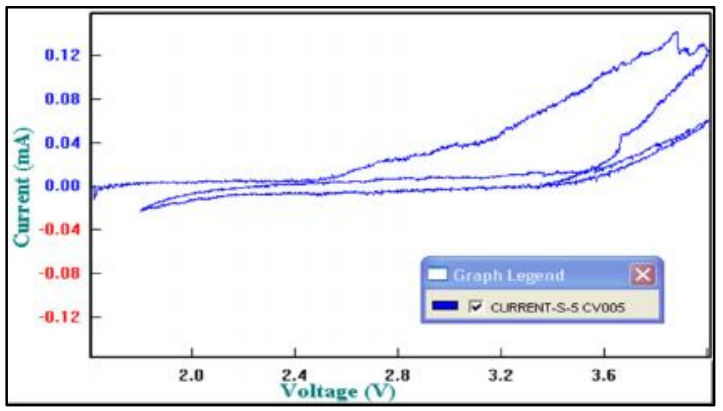

Gambar 8 Voltamagram Katoda $\mathrm{Kaca} \mathrm{LiMnPO}_{4}$ dengan 0\% $\mathrm{MnO}_{2}$

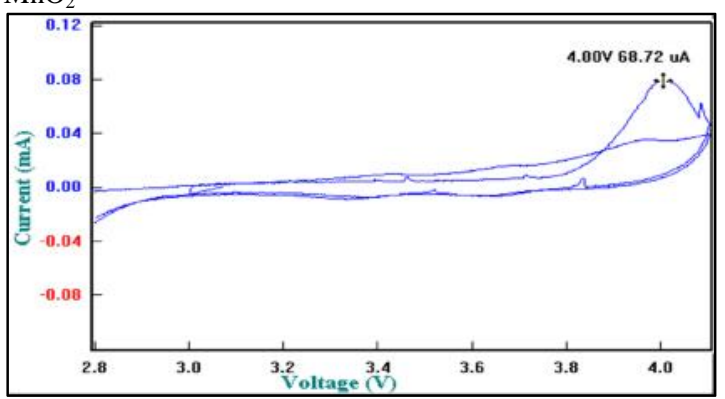

Gambar 9 Voltamagram Katoda $\mathrm{Kaca} \mathrm{LiMnPO}_{4}$ dengan $1.5 \% \mathrm{MnO}_{2}$

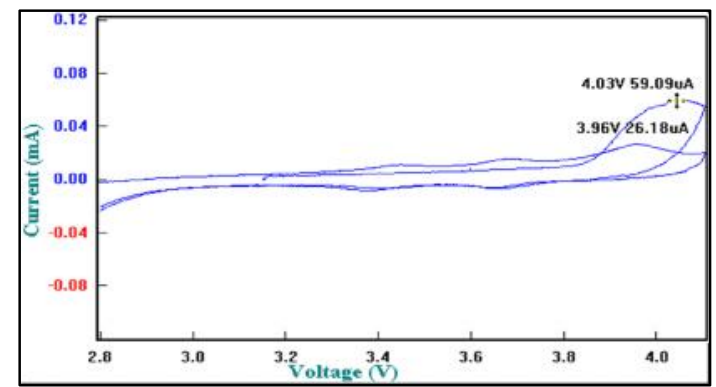

Gambar 10 Voltamagram Katoda $\mathrm{Kaca} \mathrm{LiMnPO}_{4}$ dengan $3 \% \mathrm{MnO}_{2}$

Berdasarkan ketiga voltamagram tersebut dapat terlihat bahwa ketiga sampel mengalami peak oksidasi. Reaksi oksidasi dapat terlihat pada grafik, yaitu dengan adanya peningkatan arus positif. Sedangkan peak reduksi dari ketiga 
sampel tidak begitu terlihat, namun peak tersebut tetap ada hanya nilainya terlalu kecil. Adanya proses reduksi ini dapat terlihat pada grafik, yaitu ditunjukan dengan adanya arus negatif. Peak reduksi yang rendah pada ketiga sampel menunjukkan bahwa ion $\mathrm{Li}^{+}$yang berpindah ke anoda selama proses charging, tidak semuanya kembali ke anoda ketika proses discharging.

Berdasarkan grafik cyclic voltammetry ini dapat dikatakan bahwa katoda kaca $\mathrm{LiMnPO}_{4}$ mampu mengalami oksidasi dan reduksi, walaupun nilai peak reduksinya masih sangat kecil. Kecilnya nilai peak reduksi ini kemungkinan karena katoda kaca yang dihasilkan agak sedikit basah (mengikat oksigen). Hal ini berkaitan dengan penggunaan bahan $\mathrm{P}_{2} \mathrm{O}_{5}$ yang memang merupakan bahan higroskopis. Selain itu, pada penyusunan sel baterai, elektrolit yang digunakan adalah elektrolit cair yaitu $\mathrm{LiPF}_{6}$, yang dapat membuat katoda kaca $\mathrm{LiMnPO}_{4}$ menjadi semakin basah.

Katoda kaca $\mathrm{LiMnPO}_{4}$ berhasil mengalami proses reduksi dan oksidasi, namun untuk lebih meyakinkan bahwa katoda mampu digunakan sebagai sel baterai sekunder perlu pengujian lebih lanjut yaitu pengujian charge-discharge.

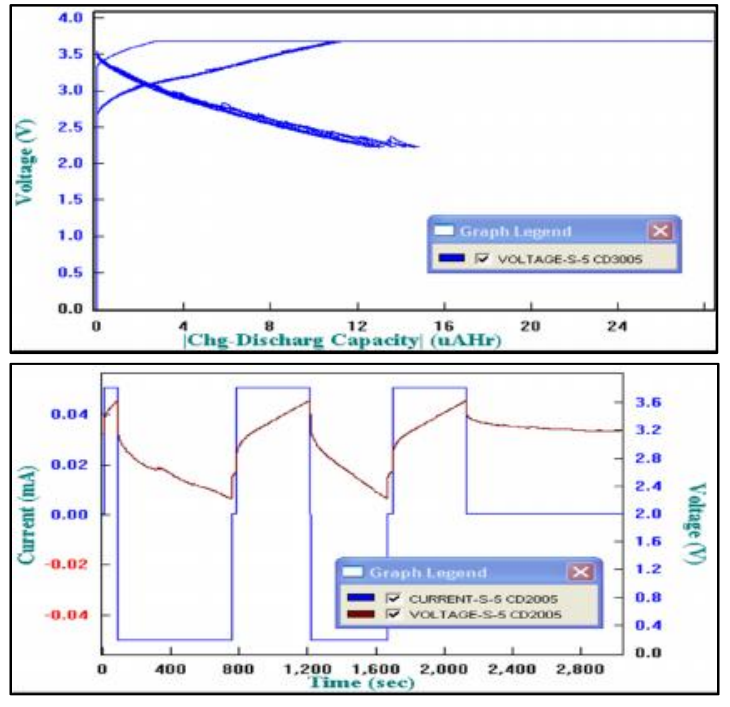

Gambar 11 Grafik pengujian charge/discharge Katoda Kaca $\mathrm{LiMnPO}_{4}$ dengan $0 \% \mathrm{MnO}_{2}$
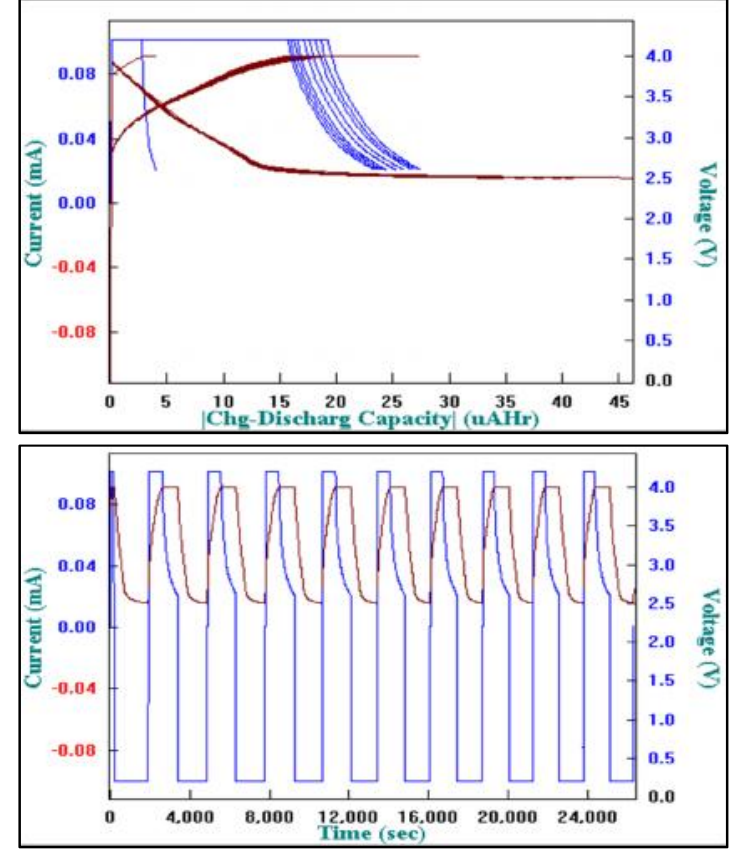

Gambar 12 Grafik pengujian charge/discharge Katoda Kaca $\mathrm{LiMnPO}_{4}$ dengan $1.5 \% \mathrm{MnO}_{2}$

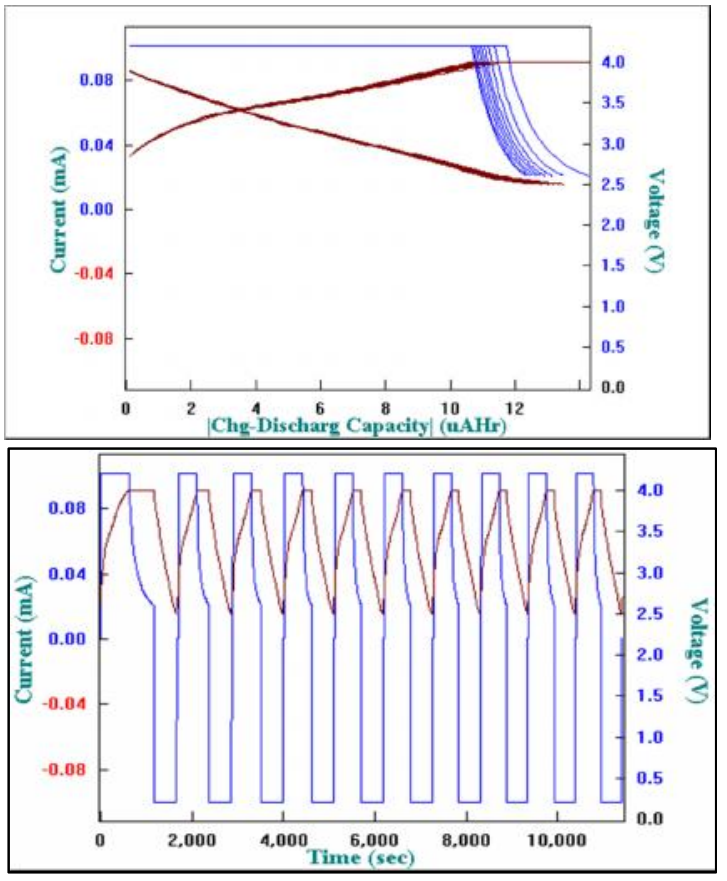

Gambar 13 Grafik pengujian charge/discharge Katoda Kaca $\mathrm{LiMnPO}_{4}$ dengan $3 \% \mathrm{MnO}_{2}$

Pada pengujian charge/discharge, diketahui bahwa semua sampel katoda kaca mengalami proses charge dan discharge, artinya katoda kaca $\mathrm{LiMnPO}_{4}$ ini sudah memenuhi syarat awal untuk diaplikasikan sebagai baterai sekunder. 
Berdasarkan grafik pengujian charge/discharge dapat diperoleh nilai tegangan kerja untuk sampel LMP-1 (komposisi $\mathrm{MnO}_{2}$ 0\%) sebesar 2,93 V, LMP-2 (komposisi $\mathrm{MnO}_{2} 1,5 \%$ ) sebesar 2,47 V dan LMP-3 (komposisi $\mathrm{MnO}_{2}$ 3\%) sebesar 3,33 V. Waktu charge /discharge dari ketiga sampel juga dapat diketahui, yaitu waktu charge dan discharge untuk sampel LMP-1 adalah 8 menit dan 12 menit, untuk sampel LMP-2 adalah 31 menit dan 25 menit, sedangkan untuk sampel LMP-3 adalah 20 menit dan 18 menit .

Grafik pengujian charge/discharge juga dapat menunjukkan nilai kapasitas dari masing-masing sampel katoda kaca $\mathrm{LiMnPO}_{4}$. Sampel dengan komposisi $\mathrm{MnO}_{2} 0 \%$ menunjukkan nilai kapasitas sebesar 16 AHr, sedangkan sampel selanjutnya menunjukkan nilai kapasitas $45 \mathrm{AHr}$, dan sampel terakhir menunjukkan nilai kapasitas sebesar 13 AHr. Katoda kaca $\mathrm{LiMnPO}_{4}$ yang dibuat berhasil menunjukkan sifat sebagai baterai sekunder karena mampu mengalami proses charge dan discharge, namun katoda ini belum berhasil menunjukkan nilai kapasitas yang baik.

Tabel 4.1 Data nilai pengujian charge/discharge katoda kaca $\mathrm{LiMnPO}_{4}$

\begin{tabular}{|l|l|l|l|l|}
\hline $\begin{array}{l}\text { Sampe } \\
1\end{array}$ & $\begin{array}{c}\text { Voc } \\
\mathrm{p} \\
\text { (V) }\end{array}$ & $\begin{array}{l}\text { Waktu } \\
\text { Charg } \\
\text { (menit } \\
\text { ) }\end{array}$ & $\begin{array}{c}\text { Waktu } \\
\text { Discharg } \\
\text { e (menit) }\end{array}$ & $\begin{array}{c}\text { Kapasita } \\
\text { s ( AHr) }\end{array}$ \\
\hline LMP 1 & 2,93 & 8 & 12 & 16 \\
\hline LMP 2 & 2,47 & 31 & 25 & 45 \\
\hline LMP 3 & 3,33 & 20 & 18 & 13 \\
\hline
\end{tabular}

\section{KESIMPULAN DAN SARAN \\ Kesimpulan}

1. Katoda kaca $\mathrm{LiMnPO}_{4}$ berhasil dibuat menggunakan metode melt quenching dengan persentase komposisi bahan $5 \mathrm{Li}_{2} \mathrm{CO}_{3}: x \mathrm{MnO}_{2}: 15 \mathrm{ZnO}:(80-$ x) $\mathrm{P}_{2} \mathrm{O}_{5}$ (dimana $\mathrm{x}=0 ; 1,5$; dan 3 dalam $\%$ mol).

2. Struktur Katoda kaca $\mathrm{LiMnPO}_{4}$ bersifat amorf untuk semua sampel, namun ada peak pengotor pada beberapa sampel, yang diduga sebagai fase $\mathrm{LiMnO}_{4}$. Besarnya nilai konduktivitas optimum pada komposisi $\mathrm{MnO}_{2}$ 1,5\%. Nilai konduktivitas tertinggi adalah sebesar $7,25 \times 10^{-4} \mathrm{~S} / \mathrm{cm}$, yaitu pada sampel katoda dengan komposisi $\mathrm{MnO}_{2}$ 1,5\% .

3. Katoda kaca $\mathrm{LiMnPO}_{4}$ memenuhi syarat sebagai katoda dalam baterai sekunder, yang ditandai dengan adanya peak oksidasi dan peak pada pengujian cyclic voltammetry dan adanya proses charge dan discharge.

\section{Saran}

1. Bahan katoda kaca yang digunakan pada penelitian ini yaitu $\mathrm{P}_{2} \mathrm{O}_{5}$ merupakan bahan higroskopik, sehingga sampel yang dihasilkan agak berair. Oleh karena itu perlu ruangan ber-AC untuk menangani bahan tersebut, serta perlu tempat penyimpanan yang bebas udara, seperti desikator dsb. Hal ini dimaksudkan untuk mencegah adanya reaksi antara bahan dengan udara.

2. Sebaiknya gunakan furnace yang inert dalam pembuatan katoda kaca $\mathrm{LiMnPO}_{4}$, hal ini agar katoda kaca yang dihasilkan mempunyai impurity yang rendah, sehingga dapat dihasilkan nilai konduktivitas yang lebih tinggi.

3. Sebaiknya gunakan elektrolit padat saat pengujian performa baterai, karena aplikasi katoda kaca $\mathrm{LiMnPO}_{4}$ adalah sebagai solid state battery, sehingga katoda dan elektrolit yang digunakan haruslah berbentuk padat.

\section{DAFTAR PUSTAKA}

[1] Jian, L., Heng, Y. S., Ming, Z. H., \& Jun, G. W. (2014). Preparation of $\mathrm{LiMn}_{0.4} \mathrm{Fe}_{0.6} \mathrm{PO}_{4} / \mathrm{C}$ Composite by A New Route Combining Solid-state Reaction with Hydrothermal Synthesis. Journal of Inorganic Materials, 29(4), 443-447.

[2] Stark, M. A. (2011). "Synthesis of Nanosized, Electrochemically Active Lithium Transition Metal Phosphates". Disertasi Universitas Ulm, Jerman. 
Journal Materials Chemistry A, 02, 6368-

[3] Widanarto, W., Sahar, M. R., Ghoshal, S. K., Mashadi, Gustiono, D., \& Effendi, M. (2014). Improved Thermal Features and Ionic Conductivity of Lithium-Zinc-Tellurite Glass Electrolytes. Malaysian Journal of Fundamental and Applied Sciences, 10(4), 207-210.

[4] Lu, Qi., Gregory, S Hutchings., Yang, Zhou., Huolin, L Xi., Haimei, Zheng., \& Feng, Jiao. (2014). Nanostructured Flexible Mg-Modified $\mathrm{LiMnPO}_{4}$ Matrix as High-rate Cathode Materials for Li-ion Batteries.
6373.

[5] Kanamura, Kiyoshi., Hirokazu Munakata., \& Yusuke Namiki. (2013). Phosphate Materials For Rechargeable Battery Applications. Phosphorus Research Bulletin, 28, 030-036.

[6] Guo, H., Wu, C., Liao, L., Xie, J., Zhang, S., Zhu, P. (2013). Performance Improvement of Lithium Manganese Phosphate by Controllable Morphology Tailoring with Acid-Engaged Nano Engineering. Inorganic Chemistry . 